\title{
USE OF DEXMEDETOMIDINE INFUSION WITH SUBANAESTHETIC DOSE OF KETAMINE FOR MINOR SURGICAL PROCEDURES: A STUDY
}

\author{
Laishram Chandralekha Singha ${ }^{1}$, Deba Gopal Pathak ${ }^{2}$, Arindam Phukan³, Prakash Jammar 4
}

1 Post Graduate Trainee, Department of Anaesthesiology, Silchar Medical College and Hospital.

2 Professor and HOD, Department of Anaesthesiology, Silchar Medical College and Hospital.

3 Post Graduate Trainee, Department of Anaesthesiology, Silchar Medical College and Hospital.

4 Post Graduate Trainee, Department of Anaesthesiology, Silchar Medical College and Hospital.

\section{ABSTRACT}

\section{BACKGROUND}

Dexmedetomidine, an $\alpha 2$ agonist is an approved drug for sedation and co-analgesia, but may cause hypotension and bradycardia. Ketamine, which provides profound analgesia and dissociative anaesthesia when used with dexmedetomidine may counteract the adverse haemodynamic effects as both have opposing actions on the cardiovascular system apart from providing satisfactory sedation and analgesia during minor surgical procedures.

\section{OBJECTIVE}

To study the sedoanalgesic efficacy and haemodynamic changes of dexmedetomidine infusion along with subanaesthetic dose of ketamine for minor surgical procedures.

\section{MATERIALS AND METHODS}

After Institutional Ethical Committee approval and informed patient consent, 30 ASA physical status I and II patients of age between 20-50 years planned for split skin grafting were selected and included in the study, which was done over a period of four months. The patients were given continuous infusion of loading dose of dexmedetomidine of $1 \mu \mathrm{g} / \mathrm{kg}$ over 10 minutes. Ketamine 0.8 $\mathrm{mg} / \mathrm{kg}$ IV was given one minute before the start of the procedure and subsequently maintained with dexmedetomidine infusion @ $0.5 \mu \mathrm{g} / \mathrm{kg} / \mathrm{hr}$. Pain and sedation score, haemodynamic changes, requirement of additional dose of ketamine, and occurrence of emergence delirium were observed.

\section{RESULTS}

The sedation level during the procedure and the pain score in the immediate postoperative period were satisfactory. 28 patients did not have any discomfort whereas 2 patients required additional $0.8 \mathrm{mg} / \mathrm{kg}$ of IV ketamine. Hypotension occurred in 3 patients and bradycardia in 2 patients. There was nausea in 2 patients whereas emergence delirium or respiratory depression was not seen in any of the patients.

\section{CONCLUSION}

Dexmedetomidine infusion with subanaesthetic dose of ketamine can be used satisfactorily for minor surgical procedures.

\section{KEYWORDS}

Skin Grafting, Dexmedetomidine, Ketamine, Emergence Delirium, Hypotension.

HOW TO CITE THIS ARTICLE: Singha LC, Pathak DG, Phukan A, et al. Use of dexmedetomidine infusion with subanaesthetic dose of ketamine for minor surgical procedures: a study. J. Evolution Med. Dent. Sci. 2016;5(58):3998-4001, DOI: $10.14260 /$ jemds/2016/915

\section{INTRODUCTION}

Split skin grafting is a minor surgical procedure involving the transplantation of skin when some of the body's skin is damaged or lost in conditions like trauma, burns, and infections. Skin grafting can be done under topical, general, spinal anaesthesia, as well as under controlled sedation.

Ketamine has been widely used as a sedative and analgesic during procedures like burn dressing changes, excision, and skin grafting, etc. Ketamine provides potent analgesia, sedation, and amnesia while maintaining cardiovascular

Financial or Other, Competing Interest: None.

Submission 14-06-2016, Peer Review 09-07-2016,

Acceptance 14-07-2016, Published 20-07-2016.

Corresponding Author:

Dr. Laishram Chandralekha Singha,

Post Graduate Trainee,

Department of Anaesthesiology,

Silchar Medical College, Ghungoor, Silchar,

Cachar-788014, Assam,

E-mail: chandralekha.singha@gmail.com

DOI: $10.14260 /$ jemds/2016/915 stability and preserving spontaneous respirations and protective airway reflexes. ${ }^{[1,2]}$ Complete analgesia permits performance of extremely painful procedures. One of the common side effects of ketamine is emergence delirium. However, there are also reports of respiratory and cardiovascular depression during ketamine sedation, which makes the vigilant monitoring of these patients very important.[3-7]

Dexmedetomidine is an $\alpha 2$ adrenoceptor agonist, which belongs to imidazole subclass. It has been approved for its use as a sedative and analgesic. It activates presynaptic $\alpha 2$ receptors in the locus coeruleus of pons, which inhibits the release of norepinephrine thus leading to sedation and hypnosis. Dexmedetomidine produces conscious sedation and it mimics natural sleep in which the patients easily transform from sleep to wakefulness when aroused. Side effects of dexmedetomidine include haemodynamic effects like hypotension and bradycardia. Activation of the receptors in 
the brain and spinal cord inhibits neuronal firing causing hypotension, bradycardia, sedation, and analgesia. [8]

Co-administration of dexmedetomidine with other anaesthetic agents, sedatives, hypnotics, or opioids is likely to cause additive effects and minimize the dose requirement it attenuates, but not completely abolishes stress-induced sympathoadrenal responses protecting the patients from noxious sympathetic stimulation and haemodynamic changes. ${ }^{[9,10,11,12]}$

It is postulated that ketamine and dexmedetomidine when used together for minor procedures like split skin grafting may provide haemodynamic stability apart from providing satisfactory sedoanalgesia. The increase in the blood pressure caused due to ketamine may counteract the hypotensive effect of dexmedetomidine. On the other hand, the reduced dose requirement of ketamine due to the concomitant use of dexmedetomidine may limit the side effects of ketamine.

This study was done to study the feasibility of the use of dexmedetomidine infusion along with subanaesthetic dose of ketamine for minor surgical procedures like split skin grafting in terms of sedoanalgesic efficacy and haemodynamic changes.

\section{MATERIALS AND METHODS}

After obtaining Institutional Ethical Committee approval and written informed consent from the patients, thirty American Society of Anaesthesiology (ASA) class I and class II patients of either sex between the age of 20-50 years planned for split skin grafting were recruited and included in the study. The study was conducted over a period of four months (November 2015-February 2016). Exclusion criteria were: patient refusal, ASA class III and above, comorbidities including hypertension, diabetes mellitus, IHD, epilepsy, psychiatric disorder, or any other systemic disease.

The adequate sample size for $95 \%$ confidence level calculated using creative research system software in accordance to the incidence of yearly split skin grafting in our institution would have been 112 . However, during the study period, 30 patients satisfying the inclusion criteria were enrolled for split skin grafting in our institution. Hence, the data of thirty patients are given in the article. Further studies with higher number of cases have to be done in the future to come to a definite conclusion.

Preprocedural evaluation included detailed preoperative history, physical examination, and laboratory investigations (Complete haemogram, RBS, serum urea, serum creatinine, ECG, and a chest $x$-ray). Procedure was explained to the patient and patient were properly counselled.

Equipments used in the study includes an infusion pump, a Boyle's anaesthesia machine with multipara monitor with all emergency drugs. On arrival in the operation theatre, IV line was secured. Standard monitoring devices like pulse oximeter, NIBP, ECG were attached and baseline reading of Heart Rate (HR), Systolic Blood Pressure (SBP), Diastolic Blood Pressure (DBP), and Peripheral Oxygen Saturation (SpO2) were recorded.

- Patients were premedicated with Inj. glycopyrrolate 0.2 mg IV, Inj. midazolam 1 mg IV, Inj. Aciloc 50 mg IV, Inj. ondansetron $4 \mathrm{mg}$ IV.

- $100 \mu \mathrm{g}$ dexmedetomidine diluted by normal saline to have a $50 \mathrm{~mL}$ filled syringe $(2 \mu \mathrm{g} / \mathrm{mL})$ was prepared. Loading dose of dexmedetomidine $1 \mu \mathrm{g} / \mathrm{kg}$ was given to the patients over a period of 10 minutes before the start of the procedure using an infusion pump.

- Inj. ketamine $0.8 \mathrm{mg} / \mathrm{kg}$ was given to the patients one minute before starting the procedure.

- Maintenance dose of dexmedetomidine infusion @ 0.5 $\mu \mathrm{g} / \mathrm{kg} / \mathrm{hr}$. was administered during the procedure via an infusion pump.

- The patients were given oxygen with a high flow oxygen mask @ 5 litres/min.

- $\quad$ If any patient felt discomfort or pain, another dose of 0.8 $\mathrm{mg} / \mathrm{kg}$ ketamine was given.

Level of sedation, pain score, and requirement of additional dose of ketamine were observed. Patients were instructed on the use of Visual Analogue Scale (VAS) self-rating method. The patients were taught to use a $10 \mathrm{~cm}$ VAS scale to assess the level of pain ( 0 -no pain to 10 -worst possible pain). A pain score of $<5$ was considered adequate analgesia. In case of inadequate analgesia or sedation, second dose of ketamine bolus $(0.8 \mathrm{mg} / \mathrm{kg})$ was given as rescue. Pain was assessed by an assistant at 30 mins, 1, 2, 3, 6, and 10 hours postoperatively.

Sedation was assessed on a 5 -point scale $[(0-4)$ ' 0 ' $=$ no sedation-patient awake and alert; 4 ' = deep sleep, difficult to arouse]. Sedation were assessed by an assistant at 5 mins, 10 mins, 20 mins after the start of the procedure, at the end of the surgery and also at 30 mins, 1, 2, and 3 hours postoperatively. Sedation score of $>2$ was considered satisfactory.

Incidence and severity of side effects like hypotension, bradycardia, nausea, vomiting, emergence delirium, and respiratory depression were also recorded during the study. Hypotension was defined as mean arterial BP $<60 \mathrm{mmHg}$ and bradycardia was defined as $\mathrm{HR}<60 / \mathrm{min}$.

In the study, quantitative data are expressed in terms of mean \pm standard deviation.

\section{RESULTS AND OBSERVATIONS}

The demographic characteristics (Age, Sex, Weight, ASA Status) of the 30 patients who completed the study are summarised in Table 1.

\begin{tabular}{|c|c|}
\hline Sex (M/F) & $17 / 13$ \\
\hline Age (yrs.) & $30.2 \pm 11.0$ \\
\hline Height (cm) & $167 \pm 8.4$ \\
\hline Weight (kg) & $64.2 \pm 12.0$ \\
\hline ASA status (I/II) & $21 / 9$ \\
\hline \multicolumn{2}{|c|}{ Table 1: Demographic Data } \\
\hline
\end{tabular}

The mean operative duration was $30.2 \pm 7.0$ mins (range 25.0-35.0 mins). The sedation score of the patients were assessed at 5 mins, 10 mins, 20 mins from start of the procedure, at the end of the procedure and also at $30 \mathrm{mins}, 1$ hr., $2 \mathrm{hr}$., and $3 \mathrm{hr}$. postoperative. It has been found that the level of sedation of the patients during the procedure was satisfactory and are summarised in table 2 .

Pain score of the patients according to VAS scale at 30 mins, $1 \mathrm{hr}$., $2 \mathrm{hr}$., and $3 \mathrm{hr}$. postoperative are found to be $2.5 \pm 0.6,2.0 \pm 0.4,0.8 \pm 0.7$, and $0.4 \pm 0.2$ respectively, which is satisfactory and are summarised in table 3 .

\begin{tabular}{|c|c|}
\hline Time & Sedation Score \\
\hline 5 mins. from start of procedure & $2.9 \pm 0.2$ \\
\hline 10 mins. from start of procedure & $2.8 \pm 0.0$ \\
\hline
\end{tabular}




\begin{tabular}{|c|c|}
\hline 20 mins. from start of procedure & $2.8 \pm 0.4$ \\
\hline At the end of procedure & $2.3 \pm 0.3$ \\
\hline 30 mins. postoperative & $1.9 \pm 0.8$ \\
\hline 1 hr. postoperative & $1.8 \pm 0.6$ \\
\hline 2 hr. postoperative & $1.0 \pm 0.7$ \\
\hline 3 hr. postoperative & $0.6 \pm 0.3$ \\
\hline \multicolumn{2}{|c|}{ Table 2: Sedation Score } \\
\hline
\end{tabular}

\begin{tabular}{|c|c|}
\hline Time after Procedure & Pain Score \\
\hline $30 \mathrm{mins}$. & $2.5 \pm 0.6$ \\
\hline $1 \mathrm{hr}$. & $2.0 \pm 0.4$ \\
\hline $2 \mathrm{hr}$. & $0.8 \pm 0.7$ \\
\hline $3 \mathrm{hr}$. & $0.4 \pm 0.2$ \\
\hline \multicolumn{2}{|c|}{ Table 3: Pain Score } \\
\hline
\end{tabular}

Side effects like nausea occurred in 2 patients, which accounts for $6.66 \%$ of the cases. Hypotension occurred in 3 patients, which accounts for $10 \%$ of the cases. The patients who developed hypotension were treated with IV fluids (Normal saline @ $10 \mathrm{~mL} / \mathrm{kg} / \mathrm{hr}$.) or vasopressor whenever necessary. Bradycardia occurred in 2 patients i.e. $6.66 \%$ and were treated with $0.6 \mathrm{mg}$ atropine IV. 2 patients required an additional dose of ketamine due to discomfort during the procedure. There was no incidence of vomiting or emergence delirium in any of the cases. None of the patients showed any sign of respiratory depression. The adverse effects are summarised in table 4 .

\begin{tabular}{|c|c|c|}
\hline Variable & No. of Patients & \% of Patient \\
\hline Nausea & 2 out of 30 & 6.66 \\
\hline Vomiting & 0 out of 30 & 0 \\
\hline Hypotension & 3 out of 30 & 10 \\
\hline Bradycardia & 2 out of 30 & 6.66 \\
\hline Emergence delirium & 0 out of 30 & 0 \\
\hline Respiratory depression & 0 out of 30 & 0 \\
\hline \multicolumn{2}{|c|}{ Table 4: Adverse Effects } \\
\hline
\end{tabular}

\section{DISCUSSION}

In this study, 30 patients underwent split skin grafting under sedation using dexmedetomidine infusion with subanaesthetic dose of ketamine.

In this study, the level of sedation of the patients during the procedure and the perioperative pain score were found to be satisfactory.

Skin grafting can be done under different modalities of anaesthesia like general anaesthesia, spinal anaesthesia, local anaesthesia, or under controlled sedation. Sedation for performing split skin grafting can been done by different drugs. This study has been conducted with an aim to study the feasibility of performing minor surgical procedures like split skin grafting using dexmedetomidine infusion along with subanaesthetic dose of ketamine. Dexmedetomidine has been said to be associated with side effect profile like hypotension and bradycardia. On the other hand, ketamine causes increase in blood pressure as well as heart rate. Hence, these two drugs when used together may counteract the actions of one another and provide a more stable haemodynamic profile than when used alone. Again, emergence delirium has been a common association with ketamine, the incidence of which may be lessened because of the lower dose of ketamine used in the study. Ketamine also causes nausea and vomiting whereas studies have shown that the use of dexmedetomidine is associated with decreased requirement of antiemetics.

The effect of ketamine is due to N-methyl-D-aspartate (NMDA) receptor antagonism, opioid receptor agonism, and voltage-sensitive sodium channel interactions.[13,14] Ketamine has been used for providing intraoperative and postoperative analgesia in burn patients. Humphries et al[5] used oral ketamine as an analgesic and sedative for wound care procedures in children with burns and found improved analgesia and sedation with oral ketamine compared with other commonly used narcotics and sedatives. Owens et al[6] in their study used IV ketamine for painful procedures in paediatric burn patients and found that ketamine can be safely and satisfactorily used for bedside procedures in paediatric burn patients. During dressing changes in burn patients, the major advantage of ketamine is that it usually preserves airway patency and respiratory function. Murat Gunduz et al found that in burn patients undergoing dressing changes, although both combinations ketamine-dexmedetomidine and ketamine-midazolam offered an effective sedoanalgesia without causing any significant side effect, the former resulted in higher sedation and lower haemodynamic discrepancy.[15] Dilek Gunay Canpolat et al found that the ketaminedexmedetomidine combination can be considered as an excellent alternative for paediatric wound dressing changes, which does not result in respiratory depression.[16] Sharanya Nama et al reported that subanaesthetic ketamine with adjunct dexmedetomidine maybe a promising therapeutic option for the treatment of acute exacerbation of CRPS.[17]

Dexmedetomidine is a highly selective $\alpha 2$ agonist, which has eight times higher specificity for receptors compared with clonidine and has been to have better haemodynamic parameters. It can be used as perioperative sedative, analgesic, and anxiolytic like benzodiazepines, but has less side effects. Dexmedetomidine is not a powerful antiemetic and it has been shown to cause much less respiratory depression than other sedatives. Co-administration of dexmedetomidine with other anaesthetic agents, sedatives, hypnotics, or opioids is likely to cause additive effects and also attenuates stress-induced sympathoadrenal responses, which protects the patients from noxious sympathetic stimulation and haemodynamic changes.[18-21]

Emergence delirium or hallucinations are the most commonly seen adverse effects of ketamine condition.[22] In this study, none of the patient experienced hallucination. Owens et al[6] in their study found that $2.9 \%$ of the patients who received ketamine during sedation experienced side effects such as desaturation, apnoea, hypotension. Walker et al[23] found that no respiratory depression associated with the use of dexmedetomidine had occurred. Taghinia et al[24] also reported that dexmedetomidine decreases the frequency of oxygen desaturation and reduces the amounts of narcotic and anxiolytic requirement. In this study, we did not observe any respiratory depression, hypoxia, or apnoea in any patient. Hypotension and bradycardia are the most frequently seen adverse effects of IV dexmedetomidine.[25] In this study, hypotension (MAP $60 \mathrm{mmHg}$ ) was observed in 3 patients (10\%), and it was treated mainly with IV fluid $(0.9 \%$ saline 5 $10 \mathrm{~mL} \mathrm{kg-1} \mathrm{h-1)} \mathrm{administration.} \mathrm{Also,} \mathrm{bradycardia} \mathrm{was}$ observed in 2 patients (6.66\%) and was treated with inj. glycopyrrolate $0.2 \mathrm{mg}$ IV. Murat Gunduz et al in their study found that in burn patients undergoing dressing changes, 
although both ketamine-dexmedetomidine combination resulted in better sedation and lower haemodynamic discrepancy than ketamine-midazolam.[15]

Ketamine is associated with increased incidence of nausea and vomiting. Green et al[22] reported that the incidence of emesis after ketamine administration was associated with increasing age. In this study, 2 patients (6.66\%) experienced nausea, but none had vomiting. Taghinia et al[24] have reported that dexmedetomidine use is associated with decreased use of antiemetics.

In conclusion, we can say that the combination of intravenous infusion of dexmedetomidine with subanaesthetic dose of ketamine provide safe and satisfactory perioperative condition for short superficial surgical procedures like spit skin grafting. The haemodynamic effects of the combination were also minimal. However, more studies with large number of patients is required to arrive at a definite conclusion.

\section{REFERENCES}

1. Corssen G, Reves JG, Stanley TH. In: Intravenous anaesthesia and analgesia. Philadelphia, PA: Lea and Febiger 1988:99-174.

2. Kim G, Green SM, Denmark TK, et al. Ventilatory response during dissociative sedation in children-a pilot study. Acad Emerg Med 2003;10(2):140-5.

3. Pagel PS, Kampine JP, Schmeling WT, et al. Ketamine depresses myocardial contractility as evaluated by the preload recruitable stroke work relationship in chronically instrumented dogs with autonomic nervous system blockade. Anaesthesiology 1992;76(4):564-72.

4. Greene CA, Gillette PC, Fyfe DA. Frequency of respiratory compromise after ketamine sedation for cardiac catheterization in patients less than 21 years of age. Am J Cardiol 1991;68(10):1116-7.

5. Humphries Y, Melson M, Gore D. Superiority of oral ketamine as an analgesic and sedative for wound care procedures in the paediatric patient with burns. J Burn Care Rehabil 1997;18(1 pt 1):34-6.

6. Owens VF, Palmieri TL, Comroe CM, et al. Ketamine: a safe and effective agent for painful procedures in the paediatric burn patient. J Burn Care Res 2006;27(2): 211-6.

7. Cederholm I, Bengtsson M, Bjorkman S, et al. A long-term high dose morphine, ketamine, and midazolam infusion in a child with burns. Br J Clin Pharmacol 1990;30(6):901-5.

8. Gertler R, Brown HC, Mitchell DH, et al. Dexmedetomidine: a novel sedative-analgesic agent. Proc (Bayl Univ Med Cent) 2001;14(1):13-21.

9. Lee SK. Clinical use of dexmedetomidine in monitored anaesthesia care. Korean J Anaesthesiol 2011;61(6): 451-2.

10. Hoy SM, Keating GM. Dexmedetomidine: a review of its use for sedation in mechanically ventilated patients in an intensive care setting and for procedural sedation. Drugs 2011;71(11):1481-501.
11. Afonso J, Reis F. Dexmedetomidine: current role in anaesthesia and intensive care. Rev Bras Anaestesiol 2012;62(1):118-33.

12. Tsai CJ, Chu KS, Chen TI, et al. A comparison of the effectiveness of dexmedetomidine versus propofol targetcontrolled infusion for sedation during fibre-optic nasotracheal intubation. Anaesthesia 2010;65(3):254-9.

13. Horvath G, Joo G, Dobos I, et al. The synergistic antinociceptive interactions of endomorphin-1 with dexmedetomidine and/or S (+)- ketamine in rats. Anaesth Analg 2001;93(4):1018-24.

14. Smith DJ, Bouchal RL, de Sanctis CA, et al. Properties of the interaction between ketamine and opiate binding sites in vivo and in vitro. Neuropharmacology 1987;26(9):125360.

15. Gunduz M, Sakallı S, Guneş Y, et al. Comparison of effects of ketamine, ketamine-dexmedetomidine and ketaminemidazolam on dressing changes of burn patients. Journal of Anaesthesiology Clinical Pharmacology 2011;27(2):220-4.

16. Canpolat DG, Esmaoglu A, Tosun Z, et al. Ketaminepropofol vs ketamine-dexmedetomidine combinations in paediatric patients undergoing burn dressing changes. Journal of Burn Care 2012;33(6):718-722.

17. Nama S, Meenan DR, Fritz WT. The use of sub-anaesthetic intravenous ketamine and adjuvant dexmedetomidine when treating acute pain from CRPS. Pain Physician 2010;13(4):365-8.

18. Ramsay MA, Savege TM, Simpson BR, et al. Controlled sedation with alphaxalone-alphadolone. BMJ 1974;2(5920):656-9.

19. Steward DJ. A simplified scoring system for the postoperative recovery room. Can Anaesth Soc J 1975;22(1):111-3.

20. Kariya N, Shindoh M, Nishi S, et al. Oral clonidine for sedation and analgesia in a burn patient. J Clin Anaesth 1998;10(6):514-7.

21. Chrysostomou C, Schmitt CG. Dexmedetomidine: sedation, analgesia and beyond. Expert Opin Drug Metab Toxicol 2008;4(5):619-27.

22. Green SM, Kuppermann N, Rothrock SG, et al. Predictors of adverse events with intramuscular ketamine sedation in children. Ann Emerg Med 2000;35(1):35-42.

23. Walker J, Maccallum M, Fischer $C$, et al. Sedation using dexmedetomidine in paediatric burn patients. J Burn Care Res 2006;27(2):206-10.

24. Taghinia AH, Shapiro FE, Slavin SA. Dexmedetomidine in aesthetic facial surgery: improving anaesthetic safety and efficacy. Plast Reconstr Surg 2008;121(1):269-76.

25. Arain SR, Ebert TJ. The efficacy, side effects and recovery characteristics of dexmedetomidine versus propofol when used for intraoperative sedation. Anaesth Analg 2002;95(2):461-6. 